\title{
DA PRÁTICA SIGNIFICANTE LEXICOGRÁFICA
}

\author{
Maria da Graça Krieger
}

RESUMO: Though dictionaires hold the appearance of lexical catalogues, they are constituted as texts with their own rules for the production of meaning. As such, they take the value of a didactic discourse that under the appearance of neutrality, exert strong influence on society's linguistic behaviors. In order to bring to light the non-neutrality (absence of neutrality) of the lexicographical discourse, the author undertakes an analysis of the entry woman in a set of dictionaires of Portuguese language from a point of view that conceives this semantic microcosm as a place of tension between the individual and the collective.

PALAVRAS-CHAVE: semiótica, dicionário, texto lexicográfico, discurso, estrutura de poder, ideologia, imagem de neutralidade.

Entre todos os textos em que os significados são signos, o dicionário é o mais inocente, o mais falsamente natural, porque a sua inocuidade e seu artifício são afixados alhures. É um concorrente ingênuo, pesado, bricolagem, engenhoso, empírico, produto falsamente neutro da reflexão lingüística.

Alain Rey

\section{INTRODUÇÃO}

Em que pese sua diversidade teórica e metodológica, a semiótica, ao se definir como uma teoria geral das linguagens, pretende uma pesquisa, cujo fim é o de analisar as práticas significantes das sociedades, através da descrição das regras de produção e de apreensão do sentido. Assim, é também de seu interesse a reflexão sobre a prática lexicográfica, concretizada na produção de dicionários.

Ao mesmo tempo, reflexões dessa ordem podem contribuir para o avanço 
da lexicografia, tanto teórica quanto prática, porque os dicionários, a despeito de tipologias variadas em que se mesclam diferentes estruturas semióticas, constituem-se em textos. Como tal, possuem regras próprias de produção de significação, apesar da sua aparência de catálogo lexical, em que, sob a forma de listagem, são registradas unidades lexicais de uma dada língua com correspondência de significados entre termo definido e seus definidores.

A rigor, trata-se de textos, de natureza metalingüística, pois resultado de uma enunciação sobre a linguagem. Nessa ótica, os dicionários assumem funções de um discurso didático, desempenhando importante papel na história das línguas, sobretudo enquanto instrumentos reguladores da manutenção e da mudança dos universos lexicais.

Em especial, os dicionários monolíngües, como são considerados lugares privilegiados de referência do conhecimento lingüístico, funcionam como parâmetros das regras do bem-dizer, assumindo o valor de código normativo dos comportamentos verbais. Nessa medida, a palavra já dicionarizada pode então ser escrita, sem ferir a sobriedade da língua.

Os dicionários, ao se constituírem em instâncias formais de legitimação do léxico, adquirem um estatuto de poder no seio das sociedades. Sua força de influências, no entanto, não nasce da gratuidade, mas de um conjunto de fatores constitutivos da produção lexicográfica, o que pode ser melhor dimensionado ao se examinarem esses textos a partir do eixo comunicativo que atualizam.

Como os usuários consultam o dicionário em busca de um saber linguístico formal e conceptual, instaura-se uma relação comunicativa em que o lexicógrafo, enquanto instância dos valores em jogo, atua como Destinador manipulador. Nessa medida, é detentor do objeto-valor — o próprio saber desejado pelos destinatários-consulentes.

Entretanto, nessa relação, o objeto-valor, devido à sua natureza modal, não é disputado pelos sujeitos, contrariamente ao que ocorre com os objetos entesouráveis, como prevê o esquema narrativo canônico da semiótica greimasiana. Na conquista cognitiva, os sujeitos do querer-saber, embora apropriem-se do objeto visado ao realizarem a consulta, não privam o Destinador do saber que possui.

Dimensiona-se, assim, um contrato enunciativo estabelecido sob a forma de uma parceria tácita, na qual o lexicógrafo não apenas mantém sua posição de sujeito do saber, como costuma ser reconhecido como detentor potencial de um saber lingüístico profundo sobre o funcionamento gramatical e semântico das línguas. Por conseguinte, o saber que transmite é geralmente inquestionável, sendo aceito como verdadeiro. Com efeito, os dicionários costumam ser consultados como oráculos que contêm a verdade das palavras, não uma verdade individual, mas coletiva, especialmente porque se representam como lugares que se limitam à reprodução dos usos e dos sentidos consagrados pelas relações léxico e cultura.

Diante da adesão dos usuários, manifestada pela aceitação do paradigma do correto, pressupõe-se que o fazer-crer, próprio de toda estrutura comunicativa, efetua-se sob a forma de um fazer persuasivo no interior do discurso lexicográfico. 
Caracteriza-se assim uma forma de manipulação que, a despeito da tradição dicionarística na vida social, não é predeterminada, mas resulta de um conjunto de mecanismos que provocam efeitos de neutralidade.

Tais mecanismos, responsáveis, em última instância, por um esquema veridictório geralmente bem sucedido, estão na base da estruturação do microuniverso constitutivo do verbete, espaço em que se configura o tradicional código lexicográfico.

Em linhas gerais, essa microestrutura, nos dicionários monolíngües, justapõe ao lexema-entrada informações relativas a etimologia, fonética, morfologia, além de uma rede de acepções que procura cobrir, através das definições, os chamados sentidos primeiros e segundos da língua geral, como também aqueles relacionados aos usos regionais e especializados que o lexema possa comportar. Integram ainda esse universo, os exemplos e as abonações que, constituindo contextualizações, funcionam como recursos de reintrodução do lexema em seu universo discursivo e, logo, como testemunhos das definições apresentadas.

Em síntese, nesse microuniverso, são selecionados e descritos diferentes traços do lexema de entrada. Trata-se de informacões julgadas necessárias ao usuário idealizado, as quais são apresentadas através de uma forma de expressão estereotipada, em que estão incluídos recursos tipográficos, como: números, pontos, colchetes, parênteses e barras e ainda os indicadores do sistema remissivo interno adotado.

Constitui-se, desse modo, uma metalinguagem com diferentes funções, cujo conjunto produz o efeito de uma ampla e imparcial descrição do funcionamento gramatical e semântico das unidades lexicais repertoriadas. Pode-se dizer que o arquétipo formal do verbete, correspondendo a uma sintaxe lexicográfica, determina, em larga medida, coerções ao discurso lexicográfico. A rigor, a sintaxe contribui para provocar efeitos de apagamento do sujeito enunciador, o que reforça a imagem de neutralidade dos dicionários.

A suposição de que as obras de referência são lugares destituídos de valorações do sujeito da enunciação é acentuada pelo esquema de representação do dizer coletivo. Vale dizer, o recurso de registrar a diversidade dos usos e sentidos, virtuais e contextualizados, de um mesmo lexema provoca a ilusão de que unicamente um macrossujeito coletivo responde pelos enunciados lexicográficos.

Por exemplo, no caso dos dicionários de língua portuguesa, aparentemente, está registrado apenas o que diz a a comunidade dos falantes do português ou um grupo dentro dela. Dessa forma, as interferências da ordem do dizer individual são, em muito, dissimuladas pela imagem de que é sempre um outro sujeito que fala, embora os enunciados definidores sejam fatos de um discurso particular.

Com o objetivo de tornar estas reflexões mais concretas, procura-se descrever algumas articulações mais finas do verbete que permitem melhor identificá-lo como um espaço discursivo que, para além de conter marcas 
sociohistóricas e ideológicas de um sujeito coletivo, reflete também as projeções da enunciação particular.

Para então explicitar a dupla face do discurso lexicográfico, inicialmente, se é levado a reconhecer a organização do verbete como um arranjo de sentidos virtuais e contextualizados de um microuniverso semântico, em conformidade com o pensamento da semiótica greimasiana:

Todo universo semântico, decomposto em lexemas, pode receber a forma de dicionário. Cada lexema, concebido como uma virtualidade de significações é suscetível de ser objeto de uma representação sêmica, distribuída, pela adjunção de semas contextuais, em tantos percursos sêmicos.

(GREIMAS \& COURTES, s.d., p.121).

Quer ao nível da virtualidade, quer ao da contextualização, os percursos sêmicos de um mesmo lexema são ordenados na microestrutura lexicográfica, podendo ser analisados em seu conjunto como um microuniverso semântico, ou ao nível do patamar discursivo dos enunciados definicionais.

Desse duplo ponto de vista, analisa-se, em uma série de dicionários, o verbete mulher, cuja descrição semântica comporta diferentes percursos sêmicos. A polissemia permite melhor analisar universos axiológicos, configurados no tratamento de um tema, como o da mulher, que atualiza controvérsias na sociedade.

\section{A MULHER DICIONARIZADA}

O corpus analisado (FONSECA, 1899), reproduzido ao final deste trabalho, foi retirado de seis dicionários de língua portuguesa, publicados entre o período de 1899 e 1992.

Bem entendido, a breve análise não visa à discussão da problemática feminina e tampouco à da qualidade dos enunciados definidores, mas somente descrever os mecanismos que articulam esse microuniverso semântico como um lugar de tensão do dizer coletivo e do individual. O microuniverso fica, portanto, circunscrito aos campos semânticos que o discurso lexicográfico analisado percorre.

Propõe-se então uma análise que, por razões metodológicas, subdivide-se em três etapas, com a finalidade de identificar respectivamente: as posições de um macrossujeito coletivo acerca do sujeito mulher e as da ordem do dizer individual. Conclusivamente, realiza-se um contraponto entre alguns dicionários como forma de ratificar o ponto de vista da não neutralidade do discurso lexicográfico.

A etapa inicial de análise incide sobre os quatro primeiros dicionários, considerando-se que, neste nível, a significação articulada é representativa das visões da sociedade e da cultura sobre o sujeito mulher. Entende-se, pois, neste plano, que os diferentes significados descritos são da ordem da enunciação coletiva, refletida nos dicionários.

No conjunto da rede de acepções dos quatro primeiros dicionários, o 
equacionamento dos significados relativos ao lexema mulher podem assim ser sintetizados:

a) a descrição do ser do ser, isto é, a mulher é definida enquanto espécie feminina do gênero humano, tal como: pessoa do sexo feminino;

b) a descrição do fazer feminino, ou seja, os papéis que a mulher assume na vida social: o de esposa e o de prostituta.

Nesse último caso, são descritas modalizações do fazer feminino, através da descrição semântica quer do lexema enquanto palavra-entrada, quer dos anexos semânticos, constituídos pelas locuções.

Muito embora nesse conjunto de dicionários encontrem-se acepções em que são contextualizados traços fisiológicos da mulher e indicados sentidos figurados, como homem efeminado, predomina a dupla conceituação já mencionada. Nessa medida, configura-se a visão cultural, segundo a qual o sexo feminino define-se apenas pela sua natureza biológica e pelos papéis sociais - o de esposa e o de prostituta - que couberam tradicionalmente à mulher. E, a rigor, nada mais fora desse restrito universo no conjunto inicial de dicionários.

Vistos sob esse plano, os dicionários representam a expressão do que a sociedade, enquanto macrossujeito, julga e diz da mulher, aparecendo o discurso lexicográfico como lugar de condensação de percursos mínimos de múltiplos dizeres. No entanto, tal processo comporta uma dimensão discursiva particular, em que a enunciação deixa suas marcas, sobretudo, nos enunciados definidores que correspondem a fatos de um discurso particular.

No próximo patamar analítico, procura-se então identificar posições individuais do enunciador, considerando o próprio contexto ideológico configurado pelos verbetes. Isso se faz com base no reconhecimento de mecanismos de discursivização dos enunciados definidores, analisando os arquilexemas empregados na categorização do sujeito mulher e, comparativamente, do sujeito homem nas mesmas obras. Neste caso, o contraponto, no interior de uma mesma formação discursiva, tem o valor de um parâmetro que permite melhor identificar as visões de mundo da instância enunciativa.

Esta etapa limita-se ao exame das acepções que definem mulher e homem, enquanto espécies do gênero humano. Tal limitação deve-se a razões de economia, mas também ao pressuposto de que os dois sexos, ao serem definidos sob a ótica do ser, recebem tratamento discursivo equivalente. Nessa medida, pressupõe-se que homem e mulher constituam os dois termos contrários do mesmo eixo semântico ser humano.

Retomando-se o Dicionário Enciclopédico da Língua Portuguesa (1899), lê-se:

Homem. s. m. O gênero humano, indivíduo do gênero humano; varão.

Mulher. s.f. fêmea do homem; esposa.

Ao se cotejarem os arquilexemas dos enunciados referentes à espécie dos seres definidos, destacados em itálico, registra-se a oposição entre o arquilexema indivíduo, no caso de homem; e fêmea, no de mulher: observa-se então que homem 
é categorizado de modo a aparecer como espécie masculina do gênero humano, enquanto mulher está relacionada à espécie animal. A distinção revela que o sexo feminino não se enquadra na categoria humana no mais antigo dos dicionários analisados.

Considerando-se ainda a articulação do eixo semântico ser humano, percebe-se que a identidade da mulher, porque discursivamente construída como fêmea do homem - não se equaciona como termo contrário a homem. Conforme propõe o dicionário, ao invés da relação de coexistência de termos contrários de um mesmo eixo semântico, articula-se uma relação hierárquica de subordinação da espécie feminina à masculina. Caso houvessse correspondência, no verbete homem, apareceria macho, ou mesmo macho da fêmea, entretanto registra-se apenas varão, lexema exclusivo da espécie masculina humana.

Já no dicionário de Séguier (1928), encontra-se:

Homem, s.m. (lat. homo). Ser humano do sexo masculino: o homem e a mulher.

Mulher: Pessoa do sexo feminino: o homem e a mulher.

Nesse segundo dicionário, registram-se também distinções lexicais nas respectivas categorizações de homem e mulher. A oposição entre ser humano e pessoa evidencia que o tratamento discursivo de mulher também não a situa no mesmo nível de homem, embora não chegue a se articular uma subcategoria feminina.

Mas, no Pequeno Dicionário (1957), não ocorre distinção lexical significativa entre os enunciados definicionais dos dois sexos, pois o arquilexema pessoa é empregado em ambos, como se pode constatar:

Homem. Pessoa adulta do sexo masculino.

Mulher. Pessoa do sexo feminino, depois da puberdade.

Apesar do nível de desigualdade ter sido atenuado em dicionário publicado mais contemporaneamente, encontra-se em obra mais recente, caso do Novo Dicionário Aurélio (1975), enunciados definidores, cuja seleção arquilexemática também não iguala homem e mulher, como se observa:

Homem. Ser humano do sexo masculino; varão.

Mulher. Pessoa do sexo feminino, após a puberdade.

Diante dessa breve amostragem, em que predomina o emprego diferenciado dos arquilexemas definidores dos dois sexos, pode-se dizer que o sujeito enunciador reitera a visão de mundo de que a mulher é um ser que, mesmo enquanto espécie do gênero humano, não se iguala ao homem.

Em síntese, o núcleo semântico dos seres homem e mulher, definidos nos enunciados lexicográficos, não constituem dois termos contrários do mesmo eixo semântico ser humano. Dessa forma, os dois lexemas examinados não formam um par opositivo; revelando-se, por conseguinte, uma hierarquia, em que o gênero masculino é determinante e o feminino aparece ao modo de uma subcategoria do primeiro. Assim as visões culturais redutoras acerca da mulher ratificam-se nesse segundo patamar analítico, em que dois percursos, o coletivo e o individual, 
confundem-se e fundam-se no mesmo sistema de valores.

A última etapa da análise, visando a avançar na ratificação do ponto de vista da não neutralidade dos dicionários, se faz ao modo da conclusão deste trabalho. Para tanto, focaliza-se o verbete mulher nos dois dicionários que complementam o corpus analisado, a saber: o Dicionário Aurélio, em sua versão revisada e aumentada (2.ed., 1986) e o Dicionário Contemporâneo de Português, de Maria Teresa Biderman, publicado em 1992. Ambos são editados em época em que o tema da mulher passa a ser objeto de discussão na vida da sociedade, resultado de importantes transformações da atuação feminina.

Quanto ao Dicionário Aurélio, registra-se expressiva reformulação na organização do verbete mulher, destacando-se procedimentos que sinalizam para uma valorização do sexo feminino, ou mesmo, uma preocupação em situá-lo no mesmo nível de importância do masculino. Vale ainda observar a quebra da tradição lexicográfica de indicar a categoria do ser apenas nos verbetes de lexemas masculinos, cabendo a seu correspondente feminino especificações de gênero e espécie.

Veja-se a primeira acepção:

Mulher. 1. $O$ ser humano do sexo feminino capaz de conceber e parir outros seres humanos e que se distingue do homem (4) por essas características.

Nesse enunciado definidor, é interessante observar:

a) o emprego, pela primeira vez, do arquilexema ser humano na categorização de mulher;

b) a distinção entre os sujeitos homem e mulher, estabelecida exclusivamente através do traço fisiológico feminino da concepção.

Esses mecanismos respondem pelo efeito de uma concepção equalitária dos dois sexos, ficando a diferença limitada à fisiologia.

A reformulação do verbete mulher na segunda versão do Novo Dicionário Aurélio, fato que não ocorre com o verbete homem, poderia ser exaustivamente descrita. Não obstante, é suficiente a estes propósitos ressaltar apenas mais duas acepções, cujos mecanismos discursivos fazem com que apareça um enunciador com visões de mundo renovadas e, ao mesmo tempo, um sujeito não comprometido com concepções tradicionais a respeito do ser e do fazer femininos. Vale dizer, a articulação discursiva provoca o efeito de que é um outro sujeito, e não o enunciador, o responsável pelos percursos semânticos, a seguir contextualizados:

Mulher:

- Mulher (1) dotada das chamadas qualidades e sentimentos femininos.

- (Deprec.) A mulher considerada corno um ser frágil, dependente, fútil, superficial ou interesseiro.

Vale ainda destacar a indicação de sentido depreciativo, antecedendo a última acepção, recurso que corrobora o efeito de negação de um sistema axiológico tradicional com o qual o enunciador de agora não mais compactua.

À guisa de conclusão deste momento analítico, comenta-se o verbete 
mulher apresentado no Dicionário do Português Contemporâneo, lembrando antes de que se trata do único texto de um enunciador feminino. Mesmo assim, a definição relativa ao ser do sujeito mulher identifica-se àquelas dos quatro primeiros dicionários analisados, revelando-se uma visão de mundo consoante à clássica concepção do sexo feminino como uma ente menor.

Apesar dessa identificação, o microuniverso semântico descrito distinguese fundamentalmente dos anteriores, na medida em que não se encontram contextualizados percursos sêmicos relativos ao papel social da mulher enquanto prostituta, mas apenas enquanto esposa.

A afirmação do papel que sugere a divinização da mulher e a negação daquele que a representa modalizada para um fazer diabólico, segundo a concepção cristã, pode ser entendida como a expressão maior da não neutralidade do discurso lexicográfico.

\section{CONSIDERAÇÕES FINAIS}

A breve análise do verbete mulher não foi senão um pretexto para concretizar a reflexão sobre uma categoria textual que, a despeito de sua aparência de inocência e neutralidade, como já assinalou Alain Rey, não se limita a reproduzir o dizer do outro. Ao contrário, institui seu próprio sistema de valores sob a representação do discurso destituído de valores do sujeito da enunciação.

Se, de longa data, já não há mais lugar para a ilusão da neutralidade, resta a tarefa de desvendar os mecanismos que a engendram e, a um tempo, a desfazem.

Entretanto, o desvelamento, mesmo parcial, encontra seu caminho a partir da concepção de que os dicionários, apesar de sua aparência de catálogo lexical, constituem textos com regras próprias de produção de significação. Nessa ótica, assumem o valor de um discurso sobre a linguagem que, determinando padrões lingüísticos, influenciam formas de dizer. Seu estatuto de poder decorre, em larga medida, da imagem de discurso competente, anônimo e imparcial.

\section{ANEXOS}

1. FONSECA, L. Simões de. Dicionário Enciclopédico da Língua Portuguesa. 2.ed. Rio de Janeiro, Paris, Garnier, 1899.

Mulher. s.f. fêmea do homem; esposa. Fig. mulheril.

2. SEGUIER, Jayme de. Dicionário Prático Ilustrado. 2.ed. rev. Porto, Lello, 1928. Mulher, s.f. (lat. mulier) Pessoa do sexo feminino: o homem e a mulher. Pessoa do sexo feminino depois da puberdade: a criança de há três anos é hoje uma mulher. Pessoa do sexo feminino, pertencente às classes populares, por opos. a senhora. 
Esposa; minha mulher. Fig. Homem efeminado, mulherengo.

3. PEQUENO DICIONÁRIO DA LÍNGUA PORTUGUESA. 10.ed. Rio de Janeiro, Civilização Brasileira, 1960.

Mulher. s.f. Pessoa do sexo feminino, depois da puberdade; esposa (aum.: mulherão, mulheraça, mulherona); — à-toa (Bras.)(pop.), — dama (Bras., Norte), - da rua ou — da-vida (Bras.), — de má nota, — de porta-de-rua (Bras., Norte), — errada, — perdida, - solteira (Bras., Ceará), — vadia, — prostituta.

4. NOVO DICIONÁRIO DA LÍNGUA PORTUGUESA. (1975).

Mulher. do lat. muliere. s.f. 1. Pessoa do sexo feminino, após a puberdade. [Aum.: mulherão, mulheraça, mulherona]. 2. Esposa (1). Mulher à toa. Bras. pop. V. meretriz. Mulher da comédia. Mulher da rótula. Mulher da rua. Mulher vadia. Bras. V. Mulher da vida. Mulher da zona. Mulher de ponta de rua. Mulher de fado. Mulher de fandango. Mulher do mundo. Mulher do pala aberto. Mulher perdida. Mulher errada. Mulher pública. Mulher vadia. Bras. pop. V. meretriz. Mulher de César. Mulher de reputação inatacável. Mulher do piolho. Bras. Fam. Mulher muito teimosa. Mulher fatal. Mulher particularmente sensual e sedutora, que provoca ou é capaz de provocar tragédias.

5. NOVO DICIONARIO DA LÍNGUA PORTUGUESA. (1986). 2.ed.

Mulher (do lat. muliere) s.f. 1. O ser humano do sexo feminino capaz de conceber e parir outros seres humanos, e que se distingue do homem (4) por essas características. 2. Esse mesmo ser humano considerado como parcela da humanidade: os direitos da mulher. (Cf. Homem (2)) 3. A mulher (1) na idade adulta. 4. Restr. Adolescente do sexo feminino que atingiu a puberdade; moça. 5. Mulher (1) dotada das chamadas qualidades e sentimentos femininos (carinho, compreensão, dedicação ao lar e à família, intuição): Como mulher, sabe apoiá-lo na justa medida. 6. A mulher (1) considerada como parceira sexual do homem. 7. Deprec. A mulher considerada como um ser frágil, dependente, fútil, superficial, ou interesseiro: O rapaz deixava-se envolver por mulheres. 8. Cônjuge do sexo feminino; a mulher (1) em relação ao marido; esposa. 9. Amante, companheira, concubina. 10. Mulher (1) que apresenta os requisitos necessários para determinadas tarefas: mulher-dona-de-casa, mulher de negócios. 11. Uma mulher (1) qualquer; dona: Quem telefonou? - Uma mulher. [Aum. nas acepç. 1,3 a 6: mulheraça. mulherão e mulherona.] 12. Mulher à-toa. Bras. pop. V. meretriz: "Papai fica na igreja vigiando: se entra mulher à-toa corre com ela." (Geraldo França de Lima, Branca Bela, p.63.) Mulher da comédia. Bras. pop. V. meretriz. 6. BIDERMAN, Maria Tereza C. Dicionário Contemporâneo de Português. Rio de Janeiro, Vozes, 1992.

mulher s.f. mulher 1. Pessoa do sexo feminino. A mulher teve seu primeiro filho. 2. A esposa do marido. A mulher de meu amigo Carlos está doente. [pl. mulheres] / cf. moça, esposa. 


\section{BIBLIOGRAFIA}

BIDERMAN, Maria Teresa C. Dicionário Contemporâneo de Português. Rio de Janeiro, Vozes, 1992.

FONSECA, L. Simões. Dicionário Enciclopédico da Língua Portuguesa. Rio de Janeiro, Paris, Garnier, 1899.

GREIMAS, A. J. \& COURTES, J. Dicionário de Semiótica. São Paulo, Cultrix, s.d.

HOLlANDA FERREIRA, Aurélio Buarque de. Novo Dicionário da Língua Portuguesa. Rio de Janeiro, Nova Fronteira, 1975.

HOLLANDA FERREIRA, Aurélio Buarque de. Novo Dicionário da Língua Portuguesa. Rio de Janeiro, Nova Fronteira, 1986.

LANDOWSKI, Eric. La société réfléchie. Paris, Seuil, 1989.

ORLANDI, Eni P. et alli. (orgs.). Gestos de leitura: da história no discurso. Campinas, UNICAMP, 1994.

PEQUENO DICIONÁRIO DA LÍNGUA PORTUGUESA. Rio de Janeiro, 1957.

$\mathrm{REY}$, A. Le lexique: images et modèles; du dictionnaire à la lexicologie. Paris, Colin, 1977.

REY-DEBOVE, Josette. Le metalangage: étude linguistique du discours sur le langage. Paris, Dictionnaires Le Robert, 1978. (Col. L'ordre de mots).

SÉGUIER, Jayme de. Dicionário Prático Ilustrado. Porto, Lello, 1928. 
Seção Livre 
